\section{Adipofascial Posterior Interosseous Reverse Flap for Soft Tissue Loss on Dorsal Aspect of the Hand}

\begin{abstract}
Soft tissue defects of hand should be carefully evaluated to determine the most appropriate alternative for coverage. Thirteen patients with soft tissue loss on dorsum of the hand were managed by reversed septo fascial Posterior Interosseous Artery (PIA) forearm flap. The largest size of the defect was $120 \times 50 \mathrm{~cm}$ all the flaps survived. The donor site was closed primarily. The flaps contoured well to the recipient site and had good cohesion and color match. The reversed posterior interosseous flap is a versatile and reliable alternative for coverage of moderate sized defects of the hand.
\end{abstract}

\section{Introduction}

Skin loss on dorsal side of the hand and fingers often necessitates creating a vascularized flap whether free, distant or regional [1]. Several flaps have been described in order to allow an appropriate reconstruction. Among these, the posterior interosseous flap is a valuable option. It is a pedicled island flap, which receives reverse-flow through anastomosis between the posterior and anterior interosseous arteries [2]. Since it was evolved in 1986 by Pentado and Zancolli, the reverse pedicled PIOA flap, gained popularity as a cruciate alternate for management of hand soft tissue loss [3,4].

Vascular anatomical variations, donor side morbidity and its distal limit to limited to the MCPJ of the fingers and the IPJ of the thumb, were frequent cons reported by multiple authors in early applications of PIOA flaps [5]

Current study represents our results with the use of reversed adipofascial posterior interosseous artery flap for reconstruction of soft-tissue defects the dorsum of the hand.

\section{Patients and Methods}

Between May 2013 and April 2016, thirteen cases of skin loss on dorsum of the hand were managed by debridement and adipofascial posterior interosseous artery flap (Figure 1).

The patients mean age was 30 years (range 6-46) years. Skin defects were between $120 \times 50 \mathrm{~cm}$ and $60 \times 35 \mathrm{~cm}$, and mean time of delay after trauma was 4.23 days (range 3-7 days). The causes of injury were occupational trauma among four cases, road traffic accident in six patients and gunshot injuries in three cases. Eleven subjects were males while two cases were females.

The right side was affected in eight cases while the left side was injured in five cases. The average of tourniquet time range 58.23 minutes (range 47-70 minutes). The average of hospital stay was four days (3-5 days)

The quality of the donor site scar rated with the Vancouver Scar Scale averaged one point ranging from zero to three points.

Verification of the distal anastomotic vessel between the anterior interosseous and PIOA $2 \mathrm{~cm}$ proximal to the wrist level using

\section{Journal of \\ Orthopedics \& Rheumatology}

\section{Nour A Khaled*}

Department of Orthopedic Surgery, Faculty of Medicine, Mansoura University Hospital, Egypt

\section{*Address for Correspondence}

Nour A Khaled, Department of Orthopedic Surgery, Manusora University Hospital, Egypt, E-mail: kk_nour@yahoo.com

Submission: 14 August, 2018

Accepted: 24 September, 2018

Published: 02 November, 2018

Copyright: (๑) 2018 Khaled NA. This is an open access article distributed under the Creative Commons Attribution License, which permits unrestricted use, distribution, and reproduction in any medium, provided the original work is properly cited.

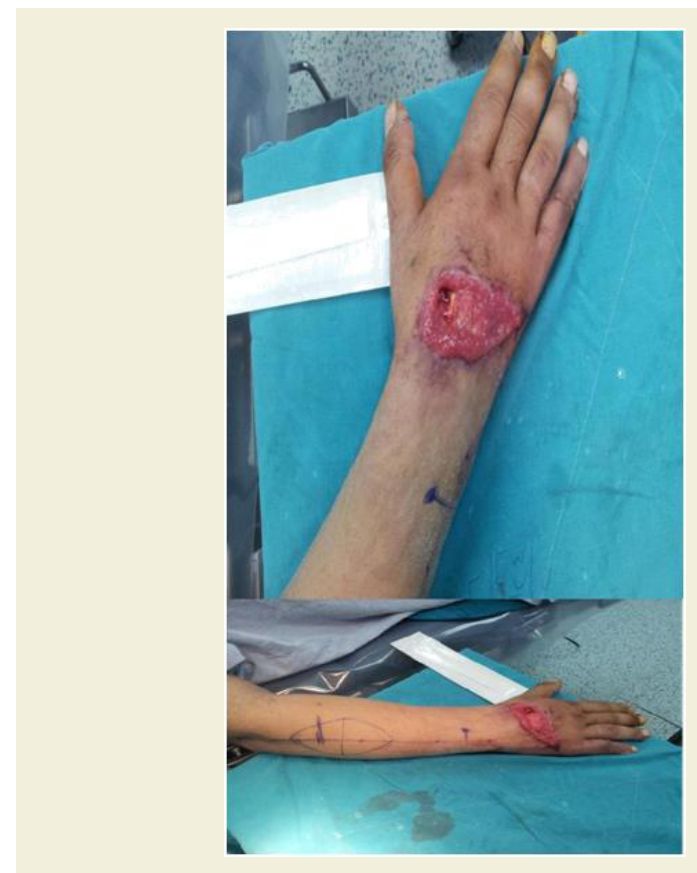

Figure 1: Skin loss at the dorsum of the hand and planning

preoperative Doppler.

The patient is positioned in supine position. The affected upper limb is positioned on an arm table, with forearm in pronation.

A pneumatic tourniquet is applied in to make the dissection easier.

A line is drawn from the ulnar styloid to the lateral epicondyle. This line is then divided in four sections. The junction of the proximal third and the distal third corresponds to the area where the septocutaneous branches of the posterior interosseous artery emerge. Septocutaneous flap including this area is thus located on the two central quarters. The skin is incised through to the antebrachial fascia. The incision starts at the distal part at the level of the distal radio-ulnar articulation, 


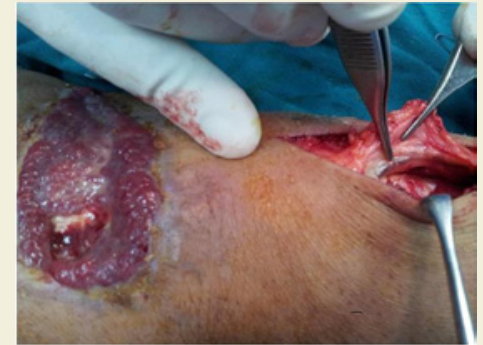

Figure 2: Posterior interosseus Artery between Extensor Carpi Ulnaris and Extensor Digiti Minimi.

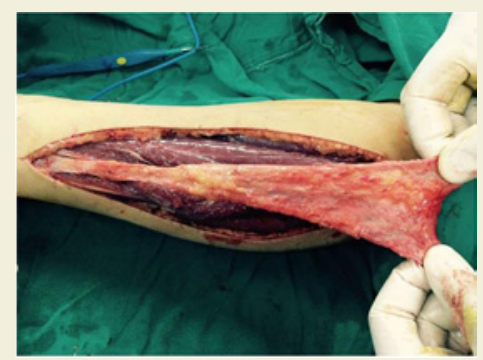

Figure 3: Adipofascial flap attached to pedicle.

allowing confirmation the presence of the anastomosis between the anterior and posterior interosseous artery. On the straight portion of the incision, the fascia is incised on the tendons of the Extensor Carpi Ulnaris (ECU) and Extensor Digiti Minimi (EDM). A fascia strip containing the septum is then isolated through to the central fascial paddle containing the perforators (Figure 2).

Then, the fascial paddle dissection is extended to the radial side. The fascia is gradually lifted from the Extensor Carpi Radialis Brevis (ECRB) and Extensor Digitorum Communis (EDC) muscles. Several septa have to be sectioned (between the ECRB and EDC and between the EDC and EDM) but we do not incise the septum between the EDM and the ECU. Lifting EDM to allow good evaluation of the septocutanous perforators, then the posterior interosseous nerve is isolated. The posterior interosseous artery is temporary closed by bulldog at its proximal part, the tourniquet is released and the perfusion of the flap is assessed. Ligation of posterior interosseous artery and rotation of flap through cutaneous tunnel with precaution to avoid rotation or kinking of pedicle. Inset of slap and secure to recipient site via interrupted absorbable sutures.finally the flap is covered with split thickness skin graft. The donor site is closed primary in layers. Bulky non-tight dressing is applied; the wrist is splinted in 10 degrees dorsiflexion.

\section{Results}

The mean hospitalization time was 2.2 days (range 1-5 days), and follow-up period was 12.8 months (range 15 days to 30 months).

All flaps survived except one case with aberrant posterior interosseous artery suffers from venous congestion and partial necrosis of the periphery of the flap. The flaps were assessed by physical examination using criteria such as temperature, turgor, color of flap and scratch test. There was neither flap ischemia nor venous congestion apart from the previous mentioned sole case. None of our cases developed infection or neurological insult.

Finally, all flaps provided adequate, viable coverage and reasonable contour. All donor sites were primary closed and left exposed at day of discharge from hospital. All patients were satisfied with the cosmetic results in long-term follow up assessments. All the facial flaps were skin grafted. The take of grafts were quite good.

\section{Discussion}

Management of soft tissue loss in the hand is technically demanding task. Reconstruction of soft tissue coverage of vital structures as vessels, nerves, tendons and bones of the hand by nonvascularized split-thickness or full-thickness skin grafting is not accepted due to adhesions, loss of soft tissue pliability, which interferes with tendon gliding and movement [6]. The use of sufficiently large, more durable and well-vascularized tissue is essential for preservation of hand function [7].

The free tissue transfer provided the advantage of supplying extensive tissue during a one-stage operation. However, there are some disadvantages such as special surgical skill, well-organized team, long hospital stay, lengthy procedure and not suitable for elderly patients with associated co-morbidies [8].

Distant flaps like abdominal or inguinal flaps provide versatile soft tissue coverage but necessitate two operative stages for flap weaning. Moreover mismatch with recipient site as regard texture, thickness and color may be cosmetic issues [9].

Regional local flaps as Chinese and ulnar perforator flaps are considered a corner stone in management of soft tissue defects in the hands but scarifying and donor site donor site morbidity are main points of criticism [10].

Distally based island fasciocutaneous flaps, as posterior interosseous artery is a thin, very versatile flap that obviate previous mentioned cons. The main advantage of the PIA flap is that, It does not jeopardize major vessels, whether radial or ulnar in contrast to Chinese and ulnar flaps. This flap is harvested on the ipsilateral injured limb avoiding further weaning and the immobilization imposed by an inguinal flap. Besides, the thickness of the subcutaneous tissue is perfectly appropriate to that of the hand. The cosmetic result at the level of the recipient site is very often satisfactory [11] (Figure $3 \& 4$ ).

Multiple authors reported draw backs for PIOA flaps as vascular

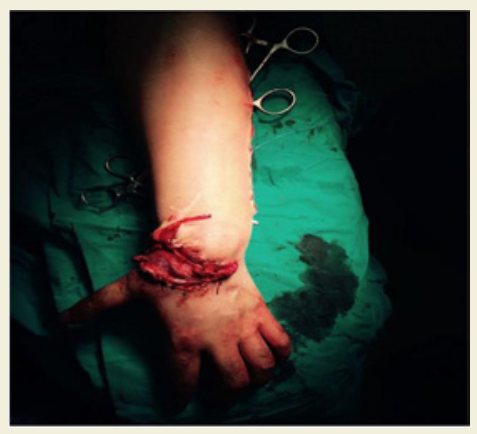

Figure 4: After flap transposition. 


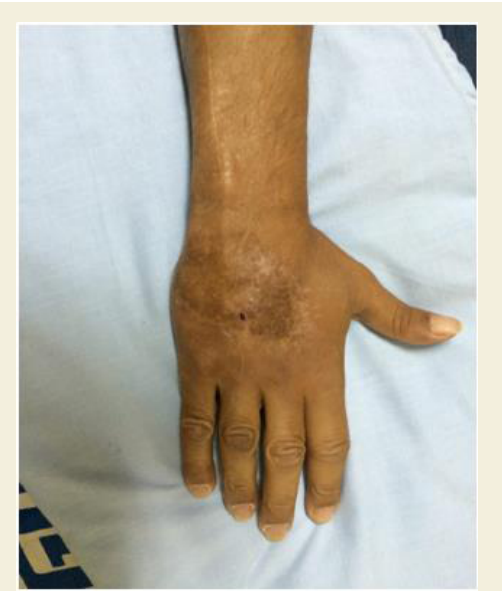

Figure 5: Post-operative 2 months follow up

anatomical variations. Angrigiani described the absence of the distal anastomosis in one of 80 cases [12], Buchler in two of 36 case, and Panteado in four of 70 cadaver specimens among their clinical series $[3,13]$. Egeand his colleague reported this variation in two cases among 19 cases of their study [14]. Another anatomical variation that may jeopardize the flap is hypoplasia and thinning of posterior interosseous artery in mid-forearm this was observed by Penteado et al. in four of seventy fresh cadavers [3]. Angrigiani et al. documented this aberrant variation in one arm among fourty fresh cadavers, and one case of eighty clinical cases [12]. This finding coincide with our observation one case with thinning of PIOA in mid- forearm.

The distal extension of the Posterior Interosseous Artery (PIA) flap is limited to the metacarpophalangeal joint of the hand, and interphalangeal joints of the thumb. Different methods have been postulated for improving the distal reach of the PIA flap. Costa et al. hyperextended the wrist to allow a composite PIA osteocutaneous flap to reconstruct the thumb [15]. Brunelli et al. exteriorized the pedicle and kept it moist by uninterrupted saline irrigation [16]. Puri et al. covered the exteriorized pedicle with a split thickness skin graft [17]. The exteriorized pedicle technique needs the wrist to be immobilized in full extension and a second procedure to divide it. Buchler et al. were able to reach theproximal IPJ by the dissection along the transverse anastomosis between interosseous arteries as advised by Bayon et al. However; this was associated with a high risk of partial loss of flap $[13,18]$.

Shibata and his colleagues extended the PIA flap proximally by including the lateral arm flap and anastomosed the proxima end of the posterior radial collateral artery and the overlying lateral arm flap territory to a recipient artery in the defect [19]. This technique is useful for larger defects that cannot be adequately covered with a standard PIA flap and requires microvascular anastomosis with its attendant risks. Fujiwara et al. harvested the PIA flap with the proximal limit $3 \mathrm{~cm}$ distal to the lateral epicondyle [20]. They lay out the flap as a spindle with a long and wide bridge, thus including more distal cutaneous perforators. They confirm the need to include the intramuscular septum, muscle, fascia, and subcutaneous veins and to evade tunneling the flap. They did not have any flap loss or congestion in their seven cases. This was the same principle of Lim and his colleagues who modified this extension of the flap by de-epitheization of the bridge segment [21].

In our series we consider adiopfascial nature of the flap adopt a wide surface area for neo-angiogenesis, enhancing the vascularity of the flap in the early postoperative era.Thus minimize venous congestion commonly encountered by multiple surgeons. We harvested the pedicle with a teeming cuff of fibrofatty tissue to preserve the accompanying veins in order to avoid venous congestion (Figure 5).

Fascial nature of the flap minimizes donor side morbidity in our series.

\section{Conclusion}

The adipofascial PIA forearm flap is reliable, safe and rapid alternative for resurfacing defects of the dorsal of the hand. Being adipofascial guarantees minimal donor side morbidity, extensile coverage.

\section{References}

1. Eberlin KR, Chang J, Curtin CM, Sammer Dm, Saint-Cyr M, et al. (2014) Soft-tissue coverage of the hand: a case-based approach. Plast Reconstr Surg 133: 91-101.

2. Prasad R, Balakrishnan TM (2015) Role of interosseous recurrent artery perforatorsin the posterior interosseous artery flap. J Hand Microsurg 7: 3641.

3. Penteado CV, Masquelet AC, Cheveral JP (1986) The anatomical basis of the fascio-cutaneous flap of the posterior interossous artery. Surg Radiol Anat 8: 209-215.

4. Zancolli EA, Agrigiani C (1988) Posterior interosseous island forearm flap. J Hand Surg Br 13: 130-135.

5. Rigot SK, Diaz-Garcia R, Debski RE, Flower J (2016) Biomechanical analysis of internal fixation methods for distal interphalangeal joint arthrodesis. Hand (N Y) 11: 221-226.

6. Ng ZY, Salgado CJ, Moran SL, Chim H (2015) Soft tissue coverage of the mangled upper extremity. Semin Plast Surg 29: 48-54.

7. Sobanko JF, Fischer J, Etzkorn JR, Miller CJ (2014) Local fasciocutaneous sliding flaps for soft-tissue defects of the dorsum of the hand. JAMA Dermatol 150: 1187-1191.

8. Uygur F, Duman H, Celikoz B (2008) Use of free anterolateral high perforator flap in the treatment of chronic postburn palmar contractures. Burns 34: $275-$ 280.

9. Adkinson JM, Chung KC (2014) Flap reconstruction of the elbow and forearm: a case-based approach. Hand Clin 30: 153-163.

10. Okochi M, Okochi H, Sakaba T, Ueda K (2017) The reconstruction of the donor site of DP flap using thoracodorsal artery perforator flap. Plast Reconstr Surg Glob Open 5: e1521.

11. Yoon CS, Noh HJ, Malzone G, Suh HS, Choi DH, et al. (2014) Posterior interosseous artery perforator-free flap: Treating intermediate-size hand and foot defects. J Plast Reconstr Aesthet Surg 67: 808-814.

12. Angigiani C, Grilli D, Domonikow D, Zancolli EA (1993) Posterior interosseous revers forearm flap: experience with 80 consecutive cases. Plast Reconstr Surg 92: 285-293.

13. Buchler U, Frey HP (1991) Retrograde posterior interosseous flap. J Hand Surg Am 16: 283-292.

14. Ege A, Tuncay I, Ercetin O (2003) Posterior interosseous artery flap in traumatic hand injuries. Arch Orthop Trauma Surg 123: 323-326.

15. Costa H, Soutar DS (1988) The distally based island posterior interosseous flap. Br J Plast Surg 41: 221-227. 
16. Brunelli F, Giele H, Perrotta R (2000) Reverse posterior interosseous flap based on an exteriorized pedicle to cover digital skin defects. J Hand Surg 25: 296-299.

17. Puri V, Mahendru S, Rana R (2007) Posterior interosseous artery flap, fasciosubcutaneous pedicle technique: a study of 25 cases. J Plast Reconstr Aesthet Surg 60: 1331-1337.

18. Bayon $P$, Pho R (1988) Anatomical basis of dorsal forearm flap. Based on posterior interosseous vessels. J Hand Surg $\mathrm{Br}$ 13: 435-439.

19. Shibata M, Iwabuchi Y, Kubota S, Matsuzaki H (1997) Comparison of free and reversed pedicled posterior interosseous cutaneous flaps. Plast Reconstr Surg 99: 791-802.

20. Fujiwara M, Kawakatsu M, Yoshida Y, Sumiya A (2003) Modified posterior interosseous flap in hand reconstruction. Tech Hand Up Extrem Surg 7: $102-$ 109.

21. Lim YJ, Sebastin SJ, Fong PL, Chong Chew WY (2010) Extending the reverse posterior interosseous artery flap using a de-epithelised bridge segment. $J$ Plast Reconstr Aesthe Surg 63: e111- e113. 